\title{
PERANCANGAN INFOGRAFIS PADA HALTE BUS ANGKUTAN CEPAT (BUS RAPID TRANSIT-BRT) TRANS-SEMARANG KORIDOR 8
}

\author{
Resa Rizkiana ${ }^{1}$, Bernardus Andang Prasetya Adiwibawa ${ }^{2}$ \\ 1,2Prodi Desain Komunikasi Visual, Fakultas Ilmu Komputer, Universitas Dian Nuswantoro \\ Jl. Imam Bonjol 207 Pendrikan Kidul, Semarang, Jawa Tengah, 50131 \\ 1rizkiana.resa@yahoo.co.id, 2andangprast@dsn.dinus.ac.id
}

\begin{abstract}
Abstrak: Transportasi massal cepat diyakini menjadi solusi dalam mengurangi tingkat kemacetan pada suatu kota ataupun negara, di Kota Semarang terdapat BRT Trans Semarang, transportasi massal yang dipercaya masyarakat sejak tahun 2009. Pada Desember 2019, BRT Trans Semarang membuka jalur baru, koridor 8, untuk memperluas layanannya. Namun demikian, di halte-halte baru di koridor tersebut belum ada fasilitas yang memudahkan penumpang untuk mendapatkan informasi. Pendekatan penelitian untuk perancangan ini menggunakan metode penelitian untuk desain Frankel dan Racine, data diperoleh melalui wawancara dan observasi serta kajian kepustakaan. Analisis data menggunakan metode framing Robert N. Entman, dimana hasilnya menunjukkan perlunya rancangan infografis untuk memberi informasi yang dibutuhkan oleh penumpang BRT Trans Semarang Koridor 8 ketika berada di shelter atau halte.
\end{abstract}

Kata kunci: Bus Angkutan Cepat, Desain, Jenis Infografis, Komunikasi Visual, Interaktif

Abstract: Rapid mass-transportation was trusted to be a solution in reducing the level of congestion in a city or country, as in Semarang City, there is the Trans Semarang BRT, mass transportation that has been trusted by the public since 2009. In December 2019, the Trans Semarang BRT opened a new route, corridor 8 , to expand its service. However, at the new shelters in this corridor, there are no facilities that make it easier for passengers to get information. The research approach for this design uses research for design methods by Frankel dan Racine, data obtained through interviews and observations, and literature review. Data analysis used Robert N. Entman's framing method, where the results indicate the need for an infographic design to provide the information needed by BRT Trans Semarang Corridor 8 passengers while at a shelter or bus stop.

Keywords: Bus Rapid Transit, Design, Infographics, Visual Communication, Interactive

\section{PENDAHULUAN}

Transportasi adalah masalah di perkotaan, khususnya di kota metropolitan yang sebagian penduduknya tinggal di wilayah suburban dan bekerja di pusat- 
pusat bisnis di tengah kota (Combs dan Rodríguez, 2014; Kaslum dan Yamin, 2017). Masalah transportasi di perkotaan tersebut, secara teoritis dipecahkan melalui penyediaan moda transportasi yang dapat dikelompokkan menjadi dua; angkutan umum konvensional (angkot, paratransit/ bus konvensional, becak, dan lain-lain) dan angkutan massal cepat (Beran, 2019).

Hingga tahun 2009, Kota Semarang masih menggunakan sistem angkutan umum konvensional. Kemudian setelah tahun 2009 itu, Pemerintah Kota Semarang, memulai menggunakan sistem angkutan massal cepat dalam bentuk Bus Angkutan Cepat (Bus Rapid Transit/BRT) atau yang populer dengan nama Bus Trans Semarang (BRT Trans Semarang, 2018) yang dikelola oleh Badan Layanan Umum (BLU) Unit Pelaksana Teknis Daerah (UPTD) Trans Semarang, sesuai Peraturan Walikota Semarang Nomor 116/2016. Bus Trans Semarang melayani 8 trayek atau koridor jalan ditambah 1 yang melayani koridor Bandara ke pusat kota (Simpang Lima) di Kota Semarang. Trayek atau koridor 8 BRT Trans Semarang, adalah koridor termuda, diresmikan pembukaannya pada 6 Desember 2019 (Fajlin, 2019) dan melintasi sejumlah obyek wisata Kota Semarang (Rismoko, 2019). Pemerintah Kota Semarang melengkapi Bus Trans Semarang koridor 8 ini dengan 42 shelter baru.

Observasi awal dan penelusuran pendapat masyarakat terhadap pembukaan Bus Trans Semarang koridor 8 menunjukkan bahwa ada beberapa masalah yang harus dibenahi. Pertama, sebagai koridor baru, niscaya mengundang penumpang baru, khususnya di sepanjang koridor untuk menggunakan layanan dan memanfaatkan shelter yang ada. Sayangnya, di dalam shelter baru yang disediakan itu, tidak terdapat cukup informasi terkait tata tertib di dalam penggunaan Bus Trans Semarang. Kedua, media informasi yang disediakan oleh pengelola di shelter-shelter lama, mengalami kerusakan atau sudah tidak mutakhir lagi. Ketiga, tidak cukupnya informasi yang tersedia bagi 
penumpang yang baru menggunakan Bus Trans Semarang, baik karena ketiadaan informasi atau rusaknya media informasi yang sudah ada, berdampak pada ketidaktepatan penumpang mengikuti prosedur serta aturan dalam menggunakan Bus Trans Semarang. Hal ini tercermin dalam pendapat para penumpang yang sempat diwawancara oleh penulis, maupun komentar penumpang pada akun resmi twitter ${ }^{T M}$ di @TransSemarang tentang koridor 8.
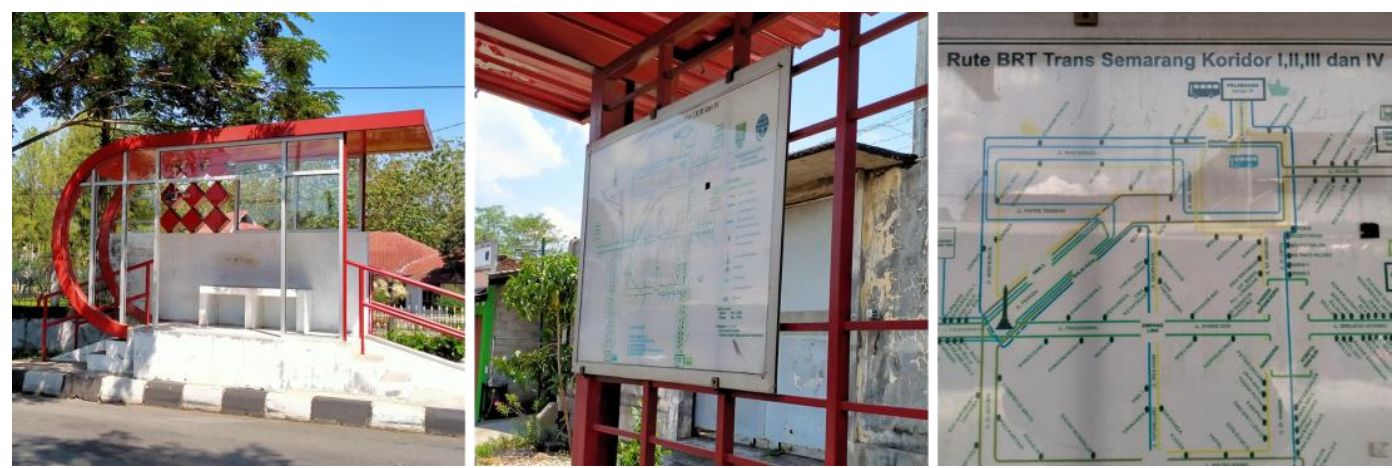

Gambar 1 : Kondisi halte yang steril dari informasi dan yang mulai rusak (tengah dan kanan)

Sumber: dokumentasi pribadi/ Adiwibawa, 2020

Di sisi lain, beberapa penelitian dan atau perancangan terkait isu seputar BRT sudah dilakukan. Tentang kualitas layanan (Putri, Yuwono dan Suprayogi, 2014; Putri dan Kusumawardhani, 2015; Rachmawati, Dwimawanti dan Rihandoyo, 2015; Salasa et al., 2015; Mirsa, 2016) membahas seputar jangkauan layanan terhadap ruang kota, headway (jarak antararmada) dan waktu tunggu, dan kepuasan pengguna. Sementara itu beberapa rancangan aplikasi digital dan sistem informasi geografis dimodelkan untuk membantu peningkatan layanan (Firmanda dan Rahardjo, 2013; Rahmandhani, Awaluddin dan Nugraha, 2018; Ardiana dan Erawan, 2019). Ada satu kajian yang membahas tentang perancangan ulang infografis bagi kaum difabel (tuli) pengguna BRT Trans-Jakarta di DKI (Rahmania, 2015). Dalam kajiannya itu Rahmania berfokus pada kekurangan kinerja infografis khususnya untuk kaum tuli. 
Perancangan media informasi yang dilakukan saat ini adalah infografis umum mengingat beberapa kebutuhan yang telah dipaparkan sebelumnya. Media infografis itu dirancang secara fisik tahan lama dan dapat menampilkan berita mutakhir, khususnya di shelter-shelter baru. Bagaimana, media informasi itu dapat memenuhi kebutuhan dan secara fisik menyatu dengan keberadaan shelter baru itu menjadi fokus perancangan ini.

\section{METODE PENELITIAN}

Frankel dan Racine, mengelompokkan penelitian desain menjadi tiga kategori; penelitian untuk desain, penelitian melalui desain dan penelitian tentang desain (Frankel dan Racine, 2010) (gambar 1). Penelitian yang dilakukan ini masuk dalam kategori pertama; penelitian untuk desain. Mengutip Downton, Frankel dan Racine mengatakan bahwa penelitian pada wilayah ini tujuannya adalah menyediakan informasi, kemungkinan-kemungkinan dampak dan data yang dapat dipakai oleh desainer untuk mencapai hasil akhir dalam proyek desainnya.

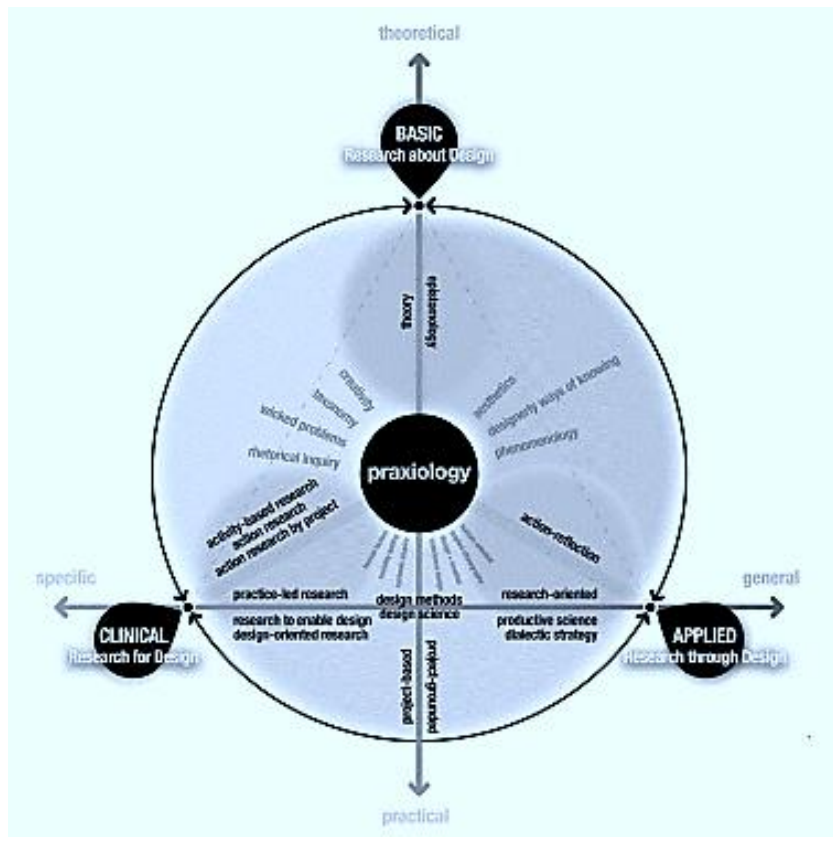

Gambar 2 : Kategori Penelitian Desain

Sumber: Frankel dan Racine, 2010 
Langkah-langkah penelitian untuk desain yang dilakukan adalah sebagai berikut; pertama, melakukan kajian kepustakaan terkait isu seputar BRT dan observasi, juga wawancara, mengenai hal tersebut. Wawancara yang dilakukan melibatkan lima informan dari kalangan pengguna BRT Trans Semarang koridor 8 untuk mendapatkan tanggapan mereka atas fasilitas yang ada, sekaligus mengkonfirmasi informasi yang diperoleh dari media sosial (akun instagram resmi BRT Trans Semarang). Wawancara kepada pengelola BRT Trans Semarang gagal dilaksanakan, karena situasi pandemi yang mulai mewabah di Semarang, oleh karena itu, informasi disandarkan pada apa yang ada di situs resmi mereka. Kajian kepustakaan dilakukan dengan mengumpulkan sejumlah literatur terkait dengan BRT. Sebagian dokumen diperoleh dari situs resmi BRT Trans Semarang, http://transsemarang.semarangkota.go.id/ dan kajian-kajian tentang transportasi massal cepat lainnya. Sementara itu, observasi dan wawancara dilakukan, khususnya pada trayek atau koridor 8, Cangkiran-Simpang Lima, berfokus pada perilaku penumpang, sarana dan prasarana yang ada dan ketepatan layanan.

Kedua, melakukan analisis atas data yang diperoleh. Analisis dilakukan dengan metode framing model Entman. Gejala yang diamati dikerangka sedemikian rupa sehingga diperoleh rekomendasi penyelesaian desainnya. Menurut Eriyanto, sebagaimana dikutip oleh Damayanti, Putra dan Mayangsari, analisis framing adalah analisis yang dipakai untuk melihat bagaimana media mengkonstruksi realitas; namun juga dipakai untuk melihat bagaimana peristiwa dipahami dan dibingkai oleh media (Damayanti, Putra dan Mayangsari, 2016).

Ketiga, menentukan kebutuhan terkait dengan keberadaan BRT Trans Semarang koridor 8. Hasil analisis framing menemukan bahwa, ada kebutuhan tentang media informasi bagi penumpang, khususnya penumpang di koridor 8 yang baru dibuka. Kebutuhan media informasi ini juga dikaitkan dengan 
keberadaan shelter atau halte yang baru dibangun serta halte lama yang sudah berkurang kualitasnya.

Keempat, melakukan kerja-kerja dengan; 1) mendaftar informasi penting apa saja yang harus tercantum dalam infografis, 2) menentukan bentuk media, 3) menyesuaikan bentuk media dengan halte yang ada, 4) finalisasi. Terkait dengan poin yang ketiga, penyesuaian bentuk media dengan halte perlu dilakukan mengingat ada beberapa variasi bentuk halte sehingga dibutuhkan bentuk media dengan gaya yang dapat dipakai untuk semua variasi bentuk halte.

\section{HASIL DAN DISKUSI}

\section{Angkutan Massal Cepat}

Angkutan massal cepat, dibutuhkan sebagai sistem layanan transportasi perkotaan karena beberapa alasan. Pertama, dari sisi lingkungan hidup, transportasi menyumbang hampir seperempat emisi gas buang (CO2), di Indonesia mencapai bagian 23 \% emisi CO2 dan merupakan penyumbang terbesar ketiga (Beran, 2019). Sementara dari studi yang dilakukan di Medan dan Semarang, menunjukkan bahwa sebagian besar moda transportasi yang digunakan oleh masyarakat di dua kota ini adalah kendaraan pribadi (49-58\% adalah kendaraan beroda dua dan $22-23 \%$ adalah kendaraan roda empat), sisanya adalah angkutan umum (Adiwinarto, 2019). Hal ini menunjukkan bahwa jika pengendara kendaraan pribadi itu beralih ke angkutan umum, emisi gas buang dapat dikurangi secara signifikan.

Kedua, dari sisi ruang kota. Keberadaan kendaraan pribadi yang besar porsinya dalam layanan transportasi perkotaan akan mengakibatkan berkurangnya ruang kota untuk transportasi. Akibat yang dirasakan langsung adalah angka kemacetan yang tinggi di kota-kota besar. Sebagai contoh di Jakarta, dalam tiga tahun terakhir, peringkat kemacetan kota ini memang menurun 
dibanding 10 kota lain di dunia dalam survey yang dilakukan oleh Tomtom Index, namun angka kemacetannya, masih tetap berkisar pada 53\% (Shalihah, 2019).

Ketiga, sistem angkutan massal cepat, dari sisi kualitas, dianggap lebih baik dari sistem angkutan umum perkotaan, yang mengandalkan moda angkutan yang bercampur dengan lalu lintas umumnya (angkot, bus tanpa jalur khusus, becak, dll.). Menurut Yoga Adiwinarto, South East Asia Director Institute for Transportation \& Development Policy, masalah yang dialami angkutan umum konvensional adalah; model bisnis yang informal yang mengakibatkan buruknya kualitas armada dan kompetisi antara pengusaha angkutan umum sehingga kinerja operasionalnya di bawah standar kelayakan. Di sisi lain, pemerintah tidak mampu mengatur tarif yang layak serta buruknya perawatan infrastruktur jalan.

Bus Rapid Transit (BRT), adalah salah satu bentuk angkutan massal cepat; di Indonesia, bentuk angkutan massal lain yang sudah tersedia yang lain adalah KRL (Kereta Rel Listrik) di Jabodetabek (Pratama, 2018), MRT (Mass Rapid Transit) di DKI Jakarta (Umasugi, 2019) dan LRT (Light Rapid Transit) di DKI Jakarta dan Palembang (Putra, 2018). Adiwinarto (2019) dan Beran (2019) dalam analisis yang terpisah menunjukkan bahwa di antara moda angkutan massal cepat, BRT memiliki keuntungan secara ekonomis dan teknis dibandingkan dengan moda angkutan massal cepat lainnya.

Terkait dengan kualitas layanan angkutan massal cepat, ada beberapa karakteristik layanan umum yang harus dipenuhi BRT, dua di antaranya adalah ketersediaan informasi yang baik dan kondisi fisik shelter BRT (Riawan, 2018). Riawan dalam studinya tentang pelayanan BRT di Kota Batam, menyebutkan bahwa ketersediaan informasi yang standar harus disediakan meliputi; a) informasi yang memuat nama halte, b) jadwal kedatangan dan keberangkatan, c) rute dan koridor, d) perpindahan koridor, e) tarif, f) peta rute. Priyanto, dalam 
analisis yang terpisah juga menyebutkan bahwa informasi tentang rute BRT menjadi hal yang penting bagi penumpang (Priyanto, 2018).

\section{Infografis}

Menurut kamus daring merriam-webster, kata infografis diketahui pertama kali digunakan pada Januari 1970 dalam sebuah buletin The Microfilm, untuk tema konferensi ke-19 National Microfilm Association. Makna infografis menurut Saptodewo, mengutip Newsom \& Haynes, adalah representasi visual dari suatu informasi yang kompleks sehingga mudah dan cepat dipahami oleh pembaca (Saptodewo, 2014). Tentang hal tersebut, Inigopatria mengingatkan untuk membedakan infografis dari visualisasi informasi (Inigopatria, 2014). Humairoh dan Prajarini mengikuti Saptodewo dan Inigopatria tentang makna infografis dengan menambah penekanan pada informasi yang direpresentasikan secara visual itu harus faktual dan aktual (Humairoh dan Prajarini, 2020).

Secara teknis, infografis dapat dibedakan menjadi beberapa kelompok; infografis manual (buatan tangan), infografis digital (dengan komputer) dan campuran keduanya (Barma, 2014). Apapun teknik yang digunakan, menurut Barma, keterampilan seni rupa khususnya ilustrasi menjadi penting, selain penguasaan aplikasi jika menggunakan teknik digital.

Dari sisi media yang dipakai, infografis dibedakan menjadi tiga; infografis statis, infografis interaktif dan infografis dinamis (Siricharoen, 2013; Siricharoen dan Vinh, 2017). Infografis statis, adalah infografis yang umum dijumpai pada surat kabar, majalah atau tabloid. Infografis interaktif adalah infografis yang memungkinkan pengguna terlibat dalam menentukan informasi apa yang dikehendaki untuk tampil. Infografis dinamis, adalah infografis yang tampil bergerak - melibatkan unsur grafis dan teks beranimasi. 


\section{BRT Trans Semarang Koridor 8}

BRT Trans Semarang Koridor 8 adalah layanan angkutan massal cepat yang baru dibuka pada 6 Desember 2019. Koridor ini menghubungkan Terminal Cangkiran, Kecamatan Mijen, Kota Semarang, terminal yang berada di bagian Selatan-Barat kota, dengan Halte Besar Simpang Lima, di pusat Kota Semarang.

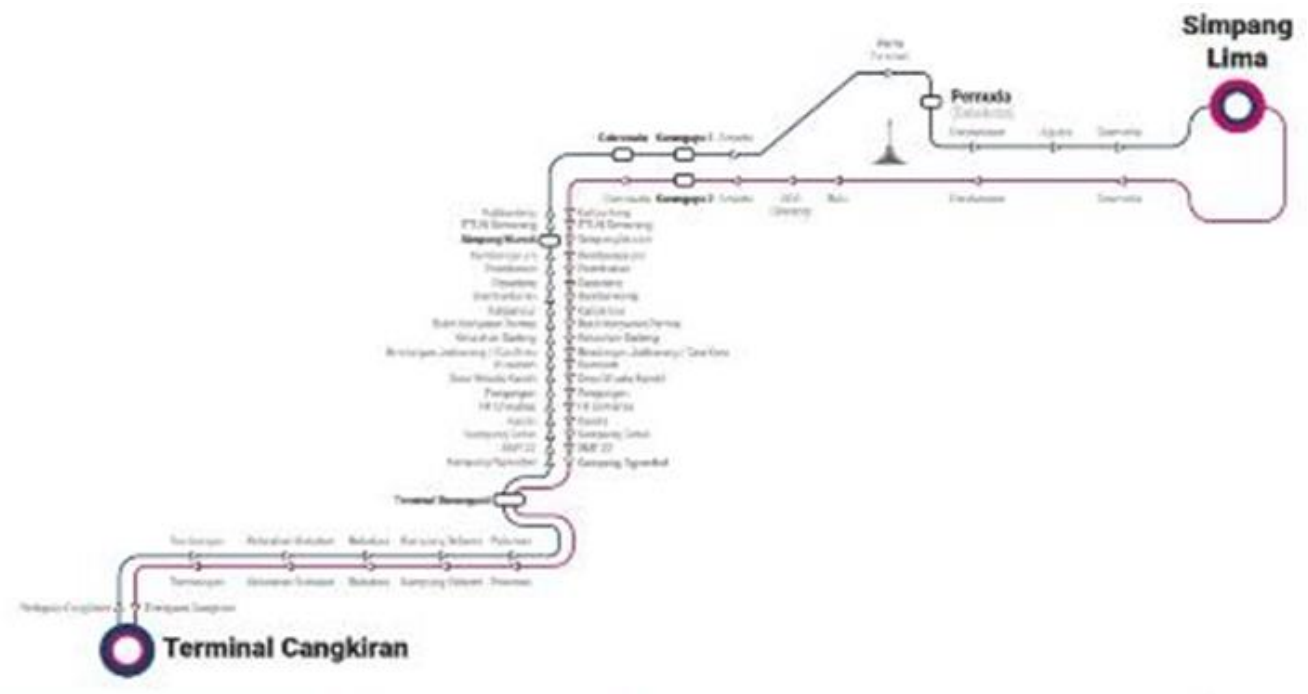

Gambar 3 : Peta Layanan BRT Koridor 8

Sumber : https://linktr.ee/transsemarang

Dari peta layanan di atas, diketahui bahwa ada total 69 halte BRT Trans Semarang di koridor 8. Dari 69 halte itu, ada 6 halte transit yang menjadi titik simpul pertemuan dengan koridor lain; penumpang yang akan berpindah koridor dapat melakukannya di halte transit ini. Ada beberapa tipe halte yang melayani penumpang di koridor 8; 2 buah halte tipe $A$ (Shelter Hebat) kemudian 62 buah halte tipe $B$ dan 4 buah halte tipe protable. Tentang tipe-tipe halte ini, ada dalam paparan yang dibuat oleh Ariawan (Ariawan, 2019). 

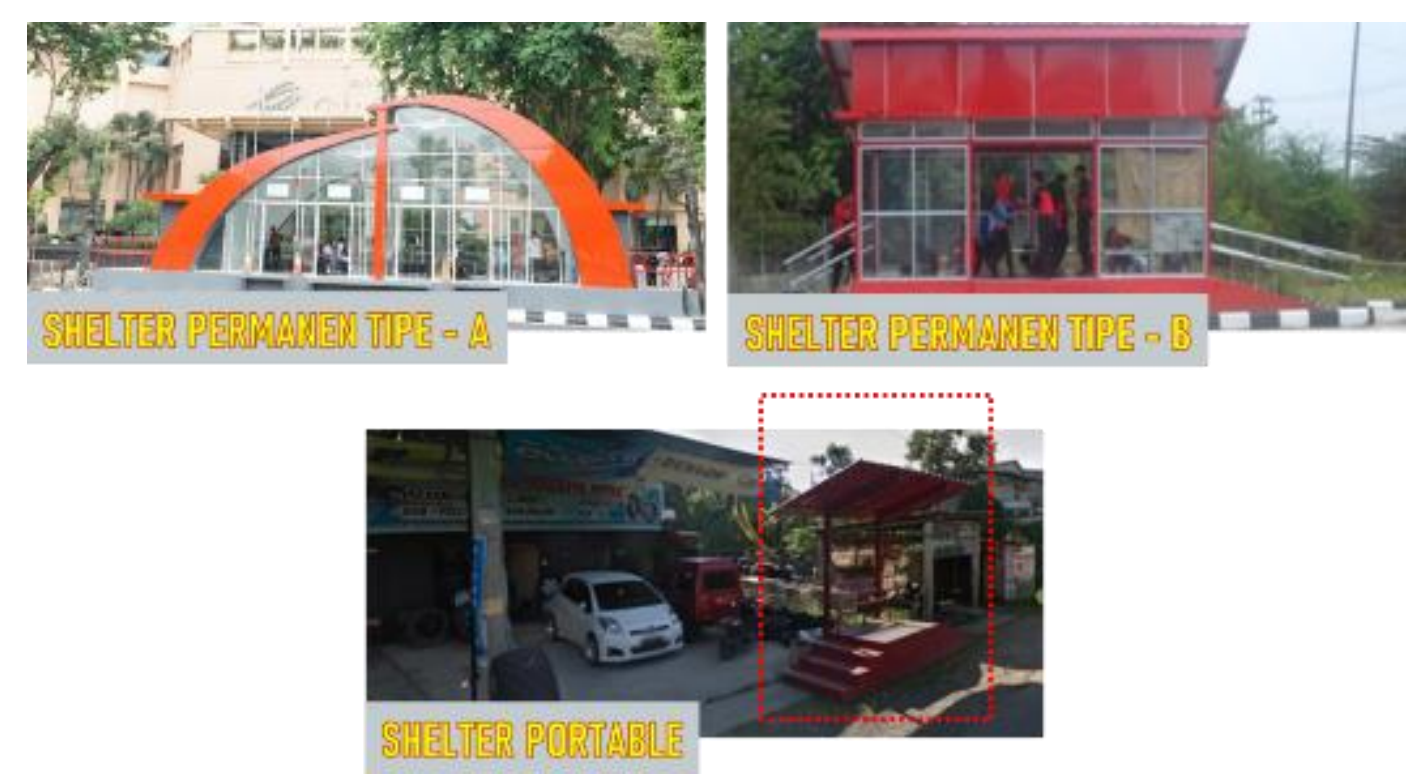

Gambar 4 : Tipe-tipe Shelter atau Halte Sumber : Ariawan, 2019

\section{Kritik dan Saran Pengguna Layanan BRT Trans Semarang Koridor 8}

Dalam observasi yang dilakukan di lapangan, kami menemui beberapa masyarakat di sekitar koridor 8 yang antusias menyambut dibukanya layanan BRT Trans Semarang di koridor ini. Meski demikian, mereka belum pernah menggunakan layanan BRT Trans Semarang dan masih belum paham rute dan halte mana saja yang dilewatinya.

Di sisi lain, dari beberapa pengguna layanan, di akun resmi Twitter $^{T M}$ @TransSemarang mencuitkan kritik mereka atas layanan BRT Trans Semarang koridor 8. Misalnya akun @Cheesec27737386 yang menyatakan keresahannya mengenai para penumpang yang enggan memberikan kursi kepada penumpang prioritas (para penyandang kebutuhan khusus, Ibu mengandung, Ibu dengan balita dan para lanjut usia/ lansia). Juga keresahannya pada perilaku penumpang yang menumpuk di dekat pintu yang berakibat pada terhambatnya proses naik-turun penumpang. 
Ada pula saran untuk meningkatkan layanan BRT Trans Semarang koridor 8. Akun @acandra2019 pada akun resmi yang sama dengan sebelumnya memberikan masukan agar pengelola BRT Trans Semarang dapat memberikan informasi rute di setiap halte dan posisi armada agar masyarakat terutama wisatawan dapat bertransportasi dengan mudah. Ini penting untuk koridor 8 mengingat jalur ini melintasi beberapa obyek wisata misalnya; Kampung Wisata Ngrembel, Goa Kreo, Waduk Jatibarang dan Kampung Wisata Kalipancur.

\section{Analisis Framing}

Dari fakta yang diperoleh melalui observasi dan wawancara dengan masyarakat di sekitar koridor 8, diketahui bahwa ada kelemahan terkait dengan kurangnya informasi. Hal ini juga didukung oleh kritik dan saran masyarakat umum yang disampaikan melalui akun resmi Pengelola BRT Trans Semarang.

Matriks analisis framing di bawah ini adalah ringkasan analisis yang telah kami lakukan. Hasilnya adalah sebagai berikut:

\section{Tabel 1 : Ringkasan Analisis Framing}

\begin{tabular}{|c|c|}
\hline $\begin{array}{r}\text { DEFINE } \\
\text { PROBLEM }\end{array}$ & $\begin{array}{l}\text { 1. Masih ada masyarakat di sekitar koridor } 8 \text { yang belum mengetahui rute dan halte BRT } \\
\text { Trans Semarang } \\
\text { 2. Masih ada pengguna layanan BRT Trans Semarang di koridor } 8 \text { yang tidak memahami } \\
\text { aturan penumpang. }\end{array}$ \\
\hline $\begin{array}{r}\text { DIAGNOSE } \\
\text { CAUSE }\end{array}$ & $\begin{array}{l}\text { 1. Tidak tersedianya informasi yang cukup di halte, terutama di halte tipe portable } \\
\text { 2. Kualitas media informasi yang buruk, terutama di halte eksisting } \\
\text { 3. Petugas yang terbatas (hanya tersedia di halte tipe A dan beberapa halte permanen } \\
\text { tipe B) }\end{array}$ \\
\hline $\begin{array}{r}\text { MAKE } \\
\text { MORAL } \\
\text { JUDGEMENT }\end{array}$ & $\begin{array}{l}\text { 1. Pengelola BRT Trans Semarang, harus melengkapi fasilitas layanan untuk membantu } \\
\text { penumpang atau calon penumpang dalam menggunakan layanan } \\
\text { 2. Ada pilihan untuk membantu penumpang misalnya; menambah jumlah personil di } \\
\text { setiap halte atau menggunakan teknologi yang efektif dan efisien }\end{array}$ \\
\hline $\begin{array}{r}\text { TREATMENT } \\
\text { RECOMMEN } \\
\text { DATION }\end{array}$ & $\begin{array}{l}\text { 1. Menyediakan media informasi dalam model campuran; konvensional maupun digital, } \\
\text { disesuaikan dengan tipe halte. } \\
\text { 2. Mengintegrasikan informasi dalam model digital dalam bentuk infografis interaktif }\end{array}$ \\
\hline
\end{tabular}




\section{Desain Infografis Konvensional}

Infografis konvensional (cetak) untuk halte-halte portabel, yang cukup banyak sebarannya. Fokus infografis ini adalah 1) tentang jalur dan halte mana saja yang ada, termasuk halte transit untuk berpindah koridor, 2) tata tertib menggunakan layanan (penumpang prioritas, batas pria dan wanita, juga ruang leluasa untuk naik-turun penumpang.

Konsep tata letak secara umum menggunakan jenis aksial dengan keseimbangan formal. Media terbagi menjadi tiga; kepala, badan dan kaki. Bagian kepala berisi judul infografis, kemudian badan adalah ruang untuk grafis dan keterangan, sedangkan kaki digunakan untuk menempatkan informasi tambahan dan kontak resmi pengelola.

Warna menggunakan konsep minimalis dengan konsep split komplementer merah marun-abu-abu tua. Tambahan warna pada grafis ilustrasi adalah warna pastel dan cream.

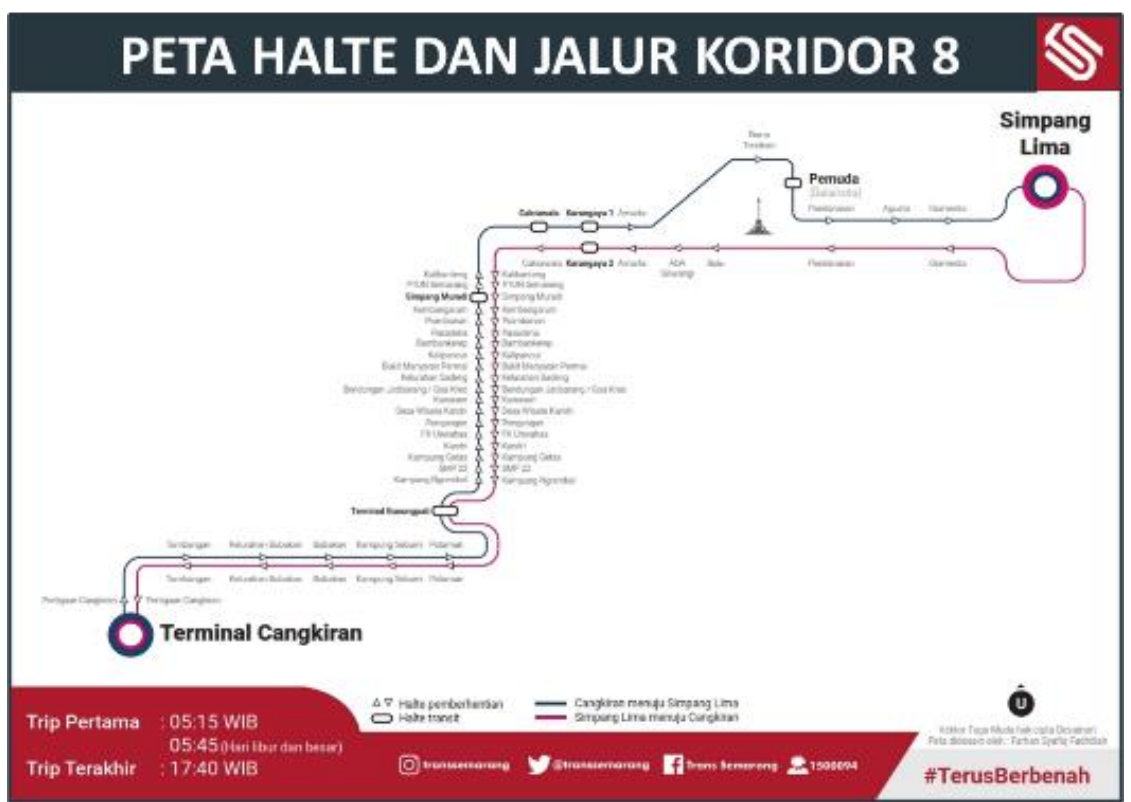

Gambar 5 : Infografis Statis/Konvensional tentang Jalur dan Halte untuk Halte Portable Sumber: Rizkiana dan Adiwibawa, 2020 


\section{TERTIB PENGGUNAAN LAYANAN}

\section{BERI TEMPAT \\ DUDUK PRIORITAS} PADA

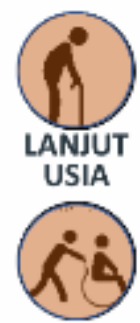

KAUM DIFABEL

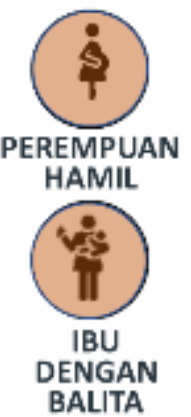

\section{BERI RUANG UNTUK NAIK-TURUN BERGESERLAH KE DEPAN/ BELAKANG}
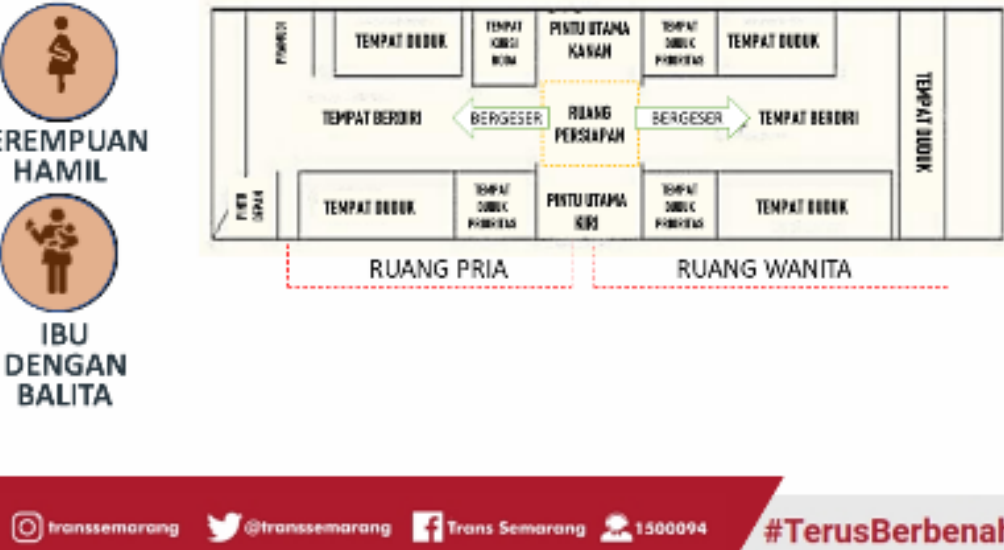

\#TerusBerbenah

Gambar 6 : Infografis Statis/Konvensional tentang Tertib Penggunaan Layanan BRT Trans Semarang untuk Halte Portable Sumber: Rizkiana dan Adiwibawa, 2020
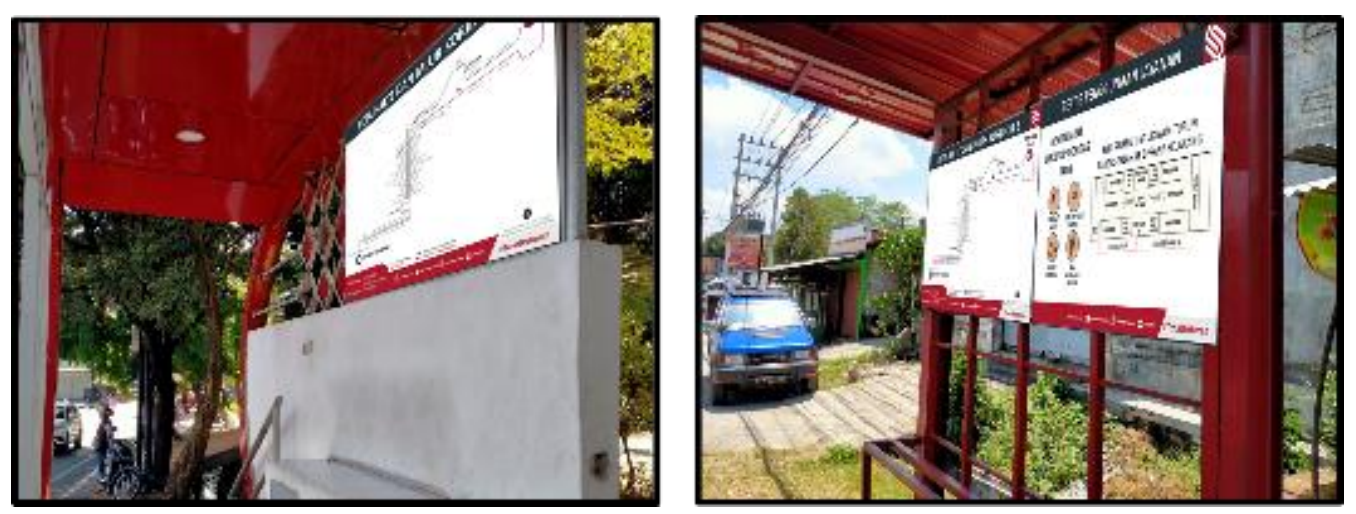

Gambar 7 : Contoh Penempatan Infografis Konvensional pada Halte Permanen Tipe B dan Halte Tipe Portable

Sumber: Rizkiana dan Adiwibawa, 2020

Gambar-gambar di atas adalah beberapa contoh infografis pokok yang harus ada di tiap halte baik halte tipe permanen maupun portable. Media yang 
digunakan adalah cetak pada kertas laminated (agar cukup awet dan tidak cepat pudar warnanya) dan diletakkan sedemikian rupa mengikuti konstruksi halte untuk menjamin keterbacaan pesan dan proporsi atas bidang halte yang berbedabeda.

\section{Desain Infografis Interaktif}

Untuk halte tipe A dan terminal, juga halte tipe B yang difungsikan juga sebagai halte transit, luasan ruang penumpang yang disediakan cukup besar. Oleh karena itu, infografis konvensional dapat digantikan dengan infografis interaktif (digital). Pertimbangannya adalah untuk membantu tugas petugas halte terutama dalam hal memberi informasi.

Melalui infografis interaktif, penumpang atau calon penumpang dapat secara mandiri melayani diri mereka mulai dari mencari informasi hingga melakukan pembayaran secara mandiri. Hal ini akan memudahkan petugas halte terutama di saat jam sibuk dengan meningkatnya jumlah penumpang.
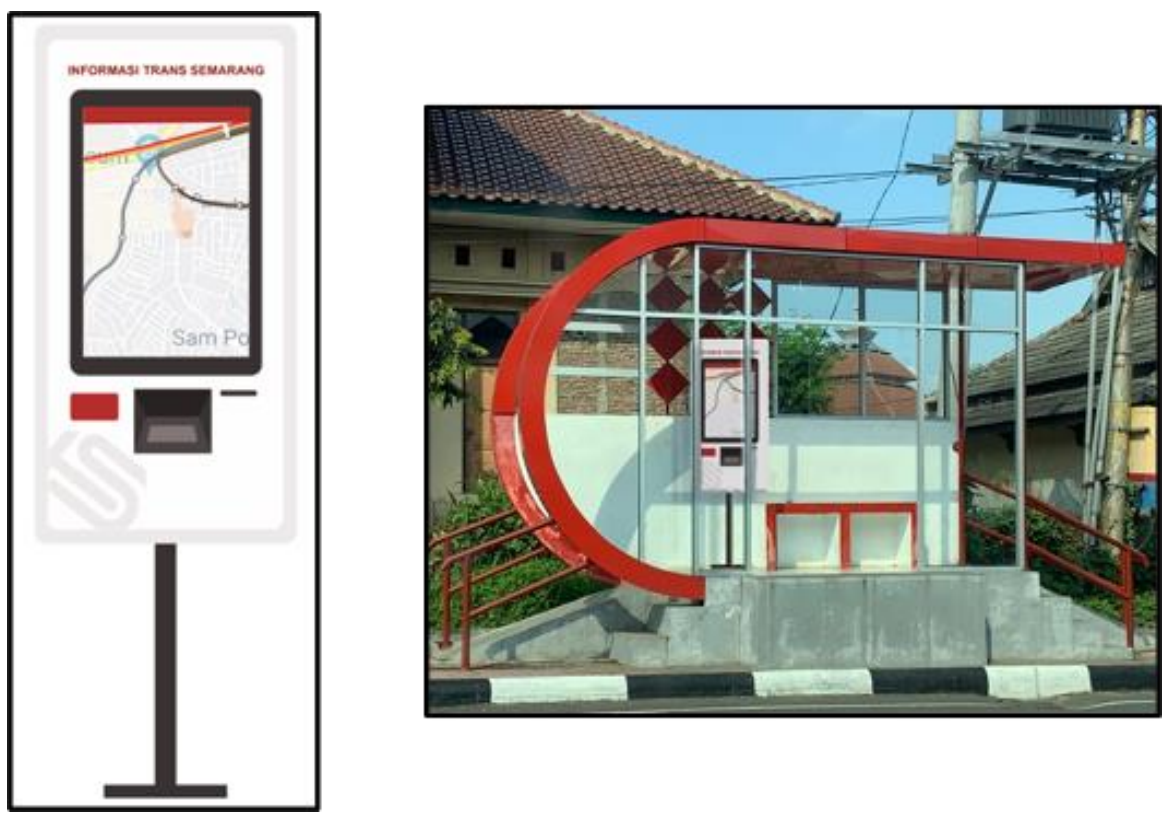

Gambar 8 : Desain Media Infografis Interaktif (kiri) dan Perletakkannya di Halte Tipe B (kanan) Sumber: Rizkiana dan Adiwibawa, 2020 
Beberapa menu yang tersedia pada infografis interaktif ini adalah: 1) Rute Koridor, 2) update Jadwal dan Posisi Bus, 3) Pembelian Tiket, 4) Tertib Penggunaan Layanan. Desain antarmuka dari infografis interaktif itu adalah sebagai berikut:
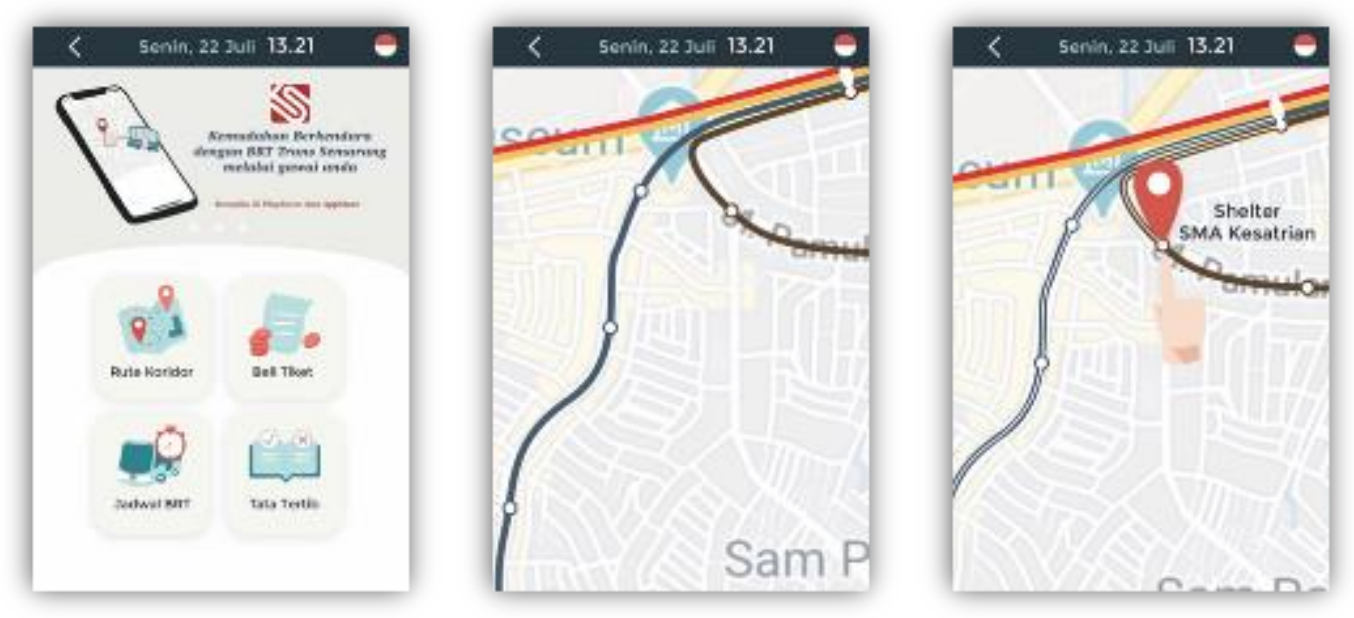

Gambar 9 : Desain Antarmuka Menu (kiri), Rute Koridor dan Posisi Halte (tengah dan kanan) Sumber: Rizkiana dan Adiwibawa, 2020
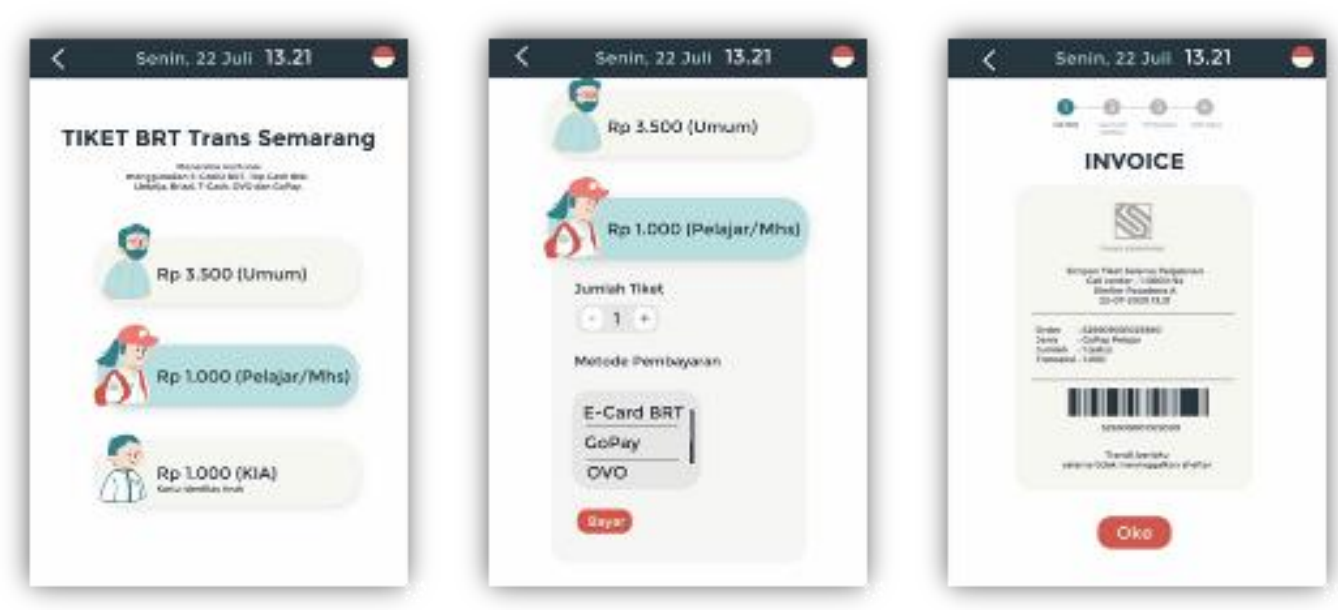

Gambar 10 : Desain Tab Pembayaran Tiket (kiri), dan Tab Berikutnya (tengah dan kanan) Sumber: Rizkiana dan Adiwibawa, 2020 

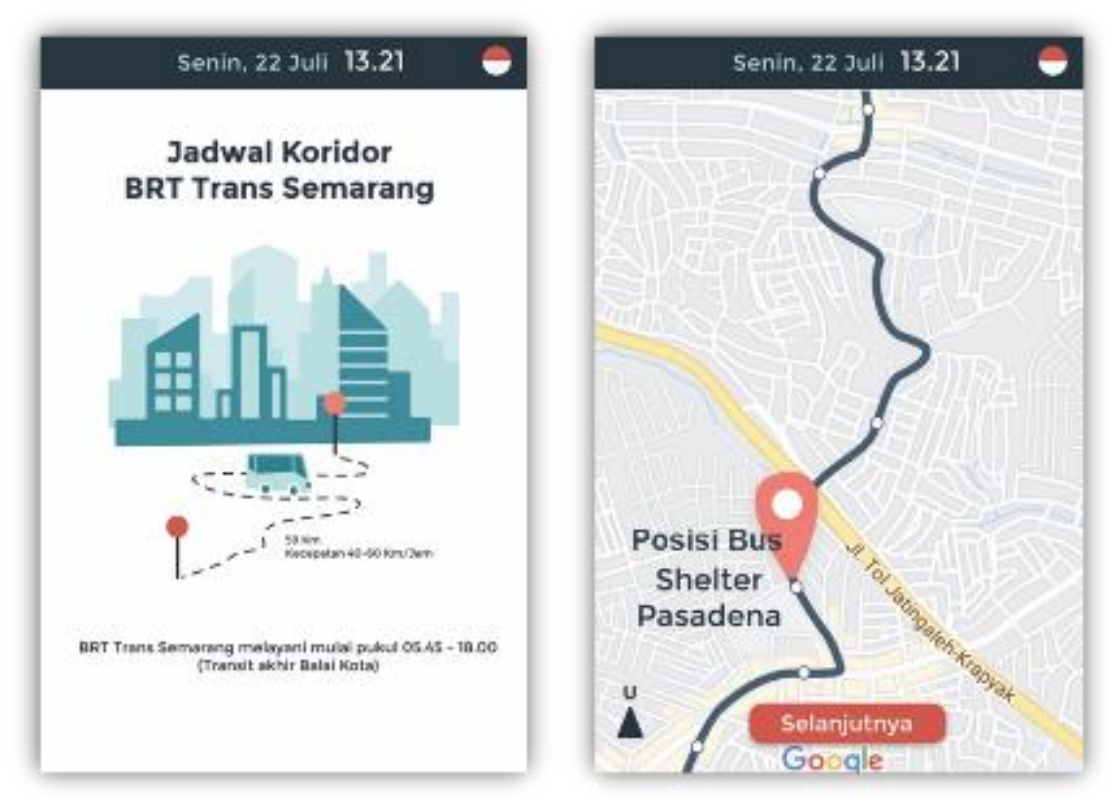

Gambar 11 : Desain Tab Jadwal Koridor (kiri), dan Tab Berikutnya - Posisi Bus (kanan)

Sumber: Rizkiana dan Adiwibawa, 2020

\section{KESIMPULAN}

Sebagai sebuah layanan yang baru diluncurkan oleh Pemerintah Kota Semarang, BRT Trans Semarang koridor 8 dari sejumlah kritik dan saran yang diberikan oleh penumpang menunjukkan beberapa kendala. Fakta di lapangan, menunjukkan bahwa kelengkapan 42 halte baru yang sebagian besar adalah halte tipe B, masih sangat kurang; tidak adanya informasi dasar yang cukup terkait dengan jalur, posisi halte dan petunjuk penggunaan layanan yang baik.

Perancangan infografis yang dibuat adalah upaya untuk melengkapi haltehalte baru yang ada. Dengan memperhatikan kondisi, tipe dan bentuk halte, maka pilihan yang paling mungkin adalah menggunakan media infografis gabungan antara infografis konvensional dengan infografis interaktif. Harapannya adalah bahwa rancangan infografis yang ada dapat membantu penumpang dalam menggunakan layanan. 
Untuk kajian lebih lanjut terkait dengan layanan angkutan massal cepat seperti BRT adalah tentang bagaimana pemeliharaan halte dalam kaitannya dengan brand produk atau jasa yang niscaya menjadi sponsor. Contoh yang menarik ada di Halte Gramedia di mana salah satu aplikasi transportasi online menjadi sponsor untuk memperbaiki halte. Hal yang mana di beberapa tahun mendatang niscaya dilakukan oleh perusahaan-perusahaan lain yang bekerjasama dengan pengelola BRT Trans Semarang. Persoalannya kemudian apakah desain halte-halte yang ada boleh diubah atau bagaimana calon sponsor itu, dengan desain yang ada menempatkan visual brand mereka.

\section{PERNYATAAN PENGHARGAAN}

Kami mengapresiasi pengelola BRT Trans Semarang, karena telah menyediakan situs jejaring yang mudah diakses dan isinya cukup membantu selesainya tulisan ini. Juga diucapkan terima kasih pada pengelola program studi DKV, Universitas Dian Nuswantoro, atas kritik dan saran hingga tulisan ini tersaji.

\section{DAFTAR PUSTAKA}

Adiwinarto, Y. (2019) "Menata Angkutan Perkotaan di Indonesia." Semarang: Institute for Transportation \& Development Policy. Tersedia pada: http://transsemarang.semarangkota.go.id/materi/4.ITDP Reformasi Angkutan Umum PPT Yoga.pdf.

Ardiana, P. P. dan Erawan, L. (2019) "Aplikasi BRT Trans Semarang Berbasis Android," JOINS (Journal of Information System), 4(2), hal. 190-202. doi: 10.33633/joins.v4i2.2625.

Ariawan, A. B. (2019) BRT Trans Semarang. Semarang: Pemerintah Kota Semarang. Tersedia

pada: 
http://transsemarang.semarangkota.go.id/materi/1.PAPARAN BRT TRANS SEMARANG.pptx.

Barma, F. W. (2014) "Variasi Teknik dan Alat dalam Membuat Infografik," in Inigopatria, S., Rianto, dan Aziz, N. A. (ed.) Indonesia Dalam Infografik; Kumpulan Infografik Kompas. First Edit. Jakarta: Kompas Media Nusantara, hal. 100-101.

Beran, U. (2019) Sustainable Urban Transport Programme Indonesia (SUTRI NAMA) and Indonesian Bus Rapid Transit Corridor Development Project (INDOBUS).

BRT Trans Semarang (2018) “Company Profile BRT BLU UPTD Trans Semarang."

Combs, T. S. dan Rodríguez, D. A. (2014) "Joint impacts of Bus Rapid Transit and urban form on vehicle ownership: New evidence from a quasi-longitudinal analysis in Bogotá, Colombia," Transportation Research Part A: Policy and Practice, 69, hal. 272-285. doi: 10.1016/j.tra.2014.08.025.

Damayanti, S., Putra, D. K. S. dan Mayangsari, I. D. (2016) "Framing Analysis of News About Jakarta' S Northern Coast Reclamation on," e-Proceeding of Management, 3(3), hal. 3928-3936. Tersedia pada: https://libraryeproceeding.telkomuniversity.ac.id/index.php/managemen t/article/view/3785.

Fajlin, E. Y. (2019) "Koridor VIII Trans Semarang Mulai Beroperasi 6 Desember.pdf." Jakarta: PT Tribun Digital Online. Tersedia pada: https://jateng.tribunnews.com/2019/11/21/koridor-viii-trans-semarangmulai-beroperasi-6-desember-ke-goa-kreo-bisa-naik-brt.

Firmanda, D. R. dan Rahardjo, N. (2013) "Sistem Informasi Geografi untuk Evaluasi Lokasi Shelter Bus Trans Semarang," Jurnal Bumi Indonesia, 2(3), hal. 175- 
184.

Tersedia

pada:

http://lib.geo.ugm.ac.id/ojs/index.php/jbi/article/view/211/207.

Frankel, L. dan Racine, M. (2010) "The Complex Field of Research: for Design, through Design, and about Design," International Conference of the Design Research Society, hal. 1-12.

Humairoh, Z. R. dan Prajarini, D. (2020) “Pengukuran Efektivitas Infografis Pada Portal Berita Online Kompas.com," Aksa: Jurnal Desain Komunikasi Visual, 3(1), hal. 379-388. doi: 10.37505/aksa.v3i1.30.

Inigopatria, S. (2014) "Infografik Adalah," in Inigopatria, S., Rianto, dan Aziz, N. A. (ed.) Indonesia Dalam Infografik; Kumpulan Infografik Kompas. First Edit. Jakarta: Kompas Media Nusantara, hal. 22-23.

Kaslum, U. dan Yamin, M. (2017) “Strategi Pengembangan Transportasi Massal Di Wilayah Suburban Makassar," Jurnal Transportasi Multimoda, 15(1), hal. 33-38.

Mirsa, K. (2016) “Kualitas Pelayanan Bus Rapid Transit ( BRT ) Trans Semarang pada Koridor I dan II," Journal of Politic and Government Studies, 5(3), hal. 1-11.

Pratama, A. N. (2018) "KRL Jakarta , dari Era Belanda hingga Hilangkan Tradisi Penumpang di Atap." Jakarta: Kompas.com. Tersedia pada: https://megapolitan.kompas.com/read/2018/09/28/13482861/krljakarta-dari-era-belanda-hingga-hilangkan-tradisi-penumpang-diatap?page=all.

Priyanto, D. F. (2018) “Analisis Respon Masyarakat Terhadap Kebijakan Aglomerasi Transportasi Massal Bus Rapid Transit (Brt) Di Kabupaten Semarang," Efficient: Indonesian Journal of Development Economics, 1(3), hal. 252259. doi: 10.15294/efficient.v1i3.27870. 
Putra, A. Y. (2018) “Ini Perbedaan LRT di Palembang dan Jakarta." Jakarta: Kompas.com. Tersedia pada: https://regional.kompas.com/read/2018/04/12/18332121/iniperbedaan-Irt-di-palembang-dan-jakarta.

Putri, S. W. dan Kusumawardhani, A. (2015) "Analisis Pengaruh Kualitas Layanan dan Nilai yang Dirasakan Terhadap Kepuasan Pelanggan BRT Trans Semarang," Diponegoro Journal of Management, 4(2), hal. 1-9.

Putri, T., Yuwono, B. dan Suprayogi, A. (2014) “Analisis Cakupan Pelayanan Shelter Bus Trans Semarang Terhadap Kawasan Cbd Menggunakan Network Analysis," Jurnal Geodesi Undip, 3(1), hal. 84212.

Rachmawati, F., Dwimawanti, I. H. dan Rihandoyo (2015) "Analisis Kualitas Pelayanan Brt Trans Semarang Koridor li Rute Terboyo - Sisemut," Journal Of Public Policy And Management Review, 4(1), hal. 61-71.

Rahmandhani, L., Awaluddin, M. dan Nugraha, A. L. (2018) "Pembuatan Aplikasi Bus Trans Semarang Berbasis Mobile GIS pada Smartphone Android," Jurnal Geodesi Undip, 7(4), hal. 8-18.

Rahmania, A. (2015) “Peranan desain komunikasi visual dalam meredesain sistem informasi pada Transjakarta dalam bentuk infografis untuk kalangan tunarungu," Skripsi-Repository Perpustakaan Universitas Trisakti. Tersedia pada: http://www.repository.trisakti.ac.id/webopac_usaktiana/index.php/hom e/detail/detail_koleksi/9/SKR/abstraksi/00000000000000082889/well test\#.

Riawan, W. A. (2018) “Analisis Pelayanan Bus Rapid Transit Kapasitas Sedang pada Sistem Transportasi Perkotaan [The Service Analysis of Medium Capacity 
Bus Rapid Transit on the Urban Transportation System]," Warta Penelitian Perhubungan, 30(2), hal. 119-132. doi: 10.25104/warlit.v30i2.688.

Rismoko, A. (2019) “Koridor 8 BRT Trans Semarang Lintasi Sejumlah Obyek Wisata.pdf." Semarang: Ayo Media Network. Tersedia pada: https://www.ayosemarang.com/read/2019/11/21/47619/koridor-8-brttrans-semarang-lintasi-sejumlah-ojek-wisata.

Salasa, W. et al. (2015) "Evaluasi Sistem Pelayanan Transit Antar Koridor," Jurnal Karya Teknik Sipil, 4(4), hal. 505-511.

Saptodewo, F. (2014) "Desain Infografis Sebagai Penyajian Data Menarik," Jurnal Desain, 01(03), hal. 193-198. Tersedia pada: http://www.erickazof.com/apa-itu-.

Shalihah, N. F. (2019) Survei 2019 , Jakarta Masuk Peringkat 10 Kota Termacet di Dunia. Jakarta. Tersedia pada: https://www.kompas.com/tren/read/2020/01/31/052816565/survei2019-jakarta-masuk-peringkat-10-kota-termacet-didunia?page=all\#page2.

Siricharoen, W. V. dan Vinh, P. C. (2017) "Question matrix method according to divided dimensions of infographics evaluation," Personal and Ubiquitous Computing. Springer London, 21(2), hal. 219-233. doi: 10.1007/s00779016-0988-7.

Siricharoen, W. V (2013) "Infogragraphics: The New communication Tools in Digital Age," The International Conference on E-Technologies and Business on the Web, (April), hal. 169-174. Tersedia pada: http://sdiwc.net/digitallibrary/infographics-the-new-communication-tools-in-digital-age.

Umasugi, R. A. (2019) “Perjalanan Panjang Megaproyek MRT di Jakarta." Jakarta: 
Resa Rizkiana, Bernardus Andang Prasetya Adiwibawa PERANCANGAN INFOGRAFIS PADA HALTE BUS ANGKUTAN CEPAT (BUS RAPID TRANSIT-BRT) TRANSSEMARANG KORIDOR 8, 194 - 215

Kompas.com. Tersedia pada: https://megapolitan.kompas.com/read/2019/03/23/09301421/perjalana n-panjang-megaproyek-mrt-di-jakarta?page=all. 